\title{
MALAREO: a user-driven project
}

\author{
Michael T. Gebreslasie, Ides Bauwens \\ School of Agricultural, Earth and Environmental Sciences, University of KwaZulu-Natal, \\ Durban, South Africa
}

\begin{abstract}
The aim of this study is to assess the capacity gaps and requirements of Earth observation (E0) and related technologies for malaria vector control and management in the Lubombo Spatial Development Initiative regions of South Africa, Swaziland and Mozambique. In order to achieve the core objective of this study, available EO data (including main characteristics and resources required to utilize them) and their potential applications for malaria epidemiology are reviewed. In addition, a survey was conducted to assess the availability of human and facility resources to operate EO and related technologies for control and management of the malaria control programs in these countries resulting in an analysis of capacity gaps, priorities and requirements. Earth observation in malaria vector control and management has two different applications: i) collection of relevant remotely sensed data for epidemiological use; and ii) direct support of ongoing malaria vector control activities. All malaria control programs and institutions recognize the significance of EO products to detect mosquito vector habitats, to monitor environmental parameters affecting mosquito vector populations as well as house mapping and distribution of information supporting residual spray planning and monitoring. It was found that only the malaria research unit (MRU) of the medical research council (MRC) in South Africa and the national
\end{abstract}

Correspondence: Michael T. Gebreslasie, School of Agricultural, Earth and Environmental Sciences, University of KwaZulu-Natal, Westville Campus, X54001 Durban, South Africa.

Tel: +27.31 .2608276 .

E-mail: gebreslasie@ukzn.ac.za

Key words: MALARE0; Malaria; Earth observation; Lubombo Spatial Development Initiative; Southern Africa.

Acknowledgements: this study was partially funded by the European Commission, under the Seventh Framework Programme (FP 7). The authors are grateful to the MALARE0 consortium.

Received for publication: 4 February 2015

Accepted for publication: 22 April 2015

(C) Copyright M.T. Gebreslasie and I. Bauwens, 2015

Licensee PAGEPress, Italy

Geospatial Health 2015; 10:329

doi:10.4081/gh.2015.329

This article is distributed under the terms of the Creative Commons Attribution Noncommercial License (by-nc 3.0) which permits any noncommercial use, distribution, and reproduction in any medium, provided the original author(s) and source are credited. malaria control program (MCP) in Swaziland currently have a fully functional geographic information systems (GIS), whereas the other surveyed MCPs in South Africa and Mozambique currently do not have this in place. Earth observation skills only exist in MRU of MRC, while spatial epidemiology is scarce in all institutions, which was identified as major gap. The survey has also confirmed that EO and GIS technologies have enormous potential as sources of spatial data and as analytical frameworks for malaria vector control. It is therefore evident that planning and management require capacity building with respect to GIS, EO and spatial epidemiology.

\section{Introduction}

The work presented here refers to a project entitled MALAREO that was funded by the European Union (EU) under its $7^{\text {th }}$ Framework Programme (FP7) for research and innovation. It comprises a mixed European-African consortium that combines many years of experience in malaria control with the European Programme for the establishment of a European capacity for Earth observation (E0), an activity that started as the Global Monitoring for Environment and Security (GMES) and is currently known under the name Copernicus (http://www.copernicus.eu/). MALARE0 is a user-driven, two-year project started in February 2011 with two main activity poles: the development of EO monitoring solutions and the building of EO and geographic information systems (GIS) capacity. The MALAREO consortium consists of small and medium enterprises (SMEs) working together with university and institutional teams with expertise in public health, epidemiology and remote sensing. It includes three European partners (Remote Sensing Solutions (RSS), Munich, Germany (http://www.rssgmbh.de/en.html), the Swiss Tropical and Public Health Institute (Swiss TPH) and EUROSENSE (EUR) Wemmel, Belgium (http://www.eurosense.com/)) and three partners in southern Africa (the Medical Research Council (MRC), Cape Town, South Africa, the University of KwaZulu-Natal (UKZN), Durban, South Africa and the national Malaria Control Programme (MCP) of Swaziland).

In 2008, the Roll Back Malaria (RBM) partnership (http://www.rollbackmalaria.org/) prepared a Global Malaria Action Plan (GMAP) in line with the 2010 targets of the UN Secretary General (Global Malaria Action Plan, 2010). Based on the global strategy to fight malaria, a clear vision was developed to reach a substantial and sustained reduction in the burden of malaria in the near future, with the view of eventual global eradication of malaria in the long term (WHO, 2011). This vision was translated into concrete, immediate goals to be achieved from 2010 to 2015 . The 2010 goal was to achieve universal coverage for all populations at malaria risk using locally, appropriate interventions for prevention and case management with result expected to reduce the malaria burden (mortality and morbidity) by at least $50 \%$ compared to the levels in 2000 (WHO, 2011). Although the original targets of 
2010 have not been fully met, important progress has been made. The Elimination 8 (E8) initiative, launched in 2009 by eight southern African countries (Angola, Botswana, Mozambique, Namibia, South Africa, Swaziland, Zambia and Zimbabwe), has stipulated a strategy to achieve universal malaria control coverage across space and time in order to eliminate malaria by 2020 (WHO, 2011; Roll Back Malaria, 2011).

To reach universal malaria control coverage, detailed knowledge on the presence of malaria is a must (Webster et al., 2005). However, this target cannot be evaluated unless the presence of malaria in space and time is known (Gemperli et al., 2004; Gething et al., 2007; Mirghani et $a l ., 2010)$. The question if the presence of malaria is spatially increasing, decreasing or stable cannot be answered with statistics alone (MARA, 1998; Kleinschmidt et al., 2000; Brooker and Utzinger, 2007), but a mapping exercise is required to indicate the number and spatial distribution of malaria cases (Smith et al., 1995; Omumbo et al., 1997). The detailed mapping of malaria risk areas at the local level is a challenge and involves different techniques. GIS, E0, Global Positioning Systems (GPS) and spatial statistics can play a major and complementary role in this regard (Hayes et al., 1985; Snow et al., 1999; Hay et al., 2000; Tanser and Le Sueur, 2002; Sipe and Dale, 2003). Analyses resulting from a combination of GIS and EO have improved our knowledge of the biodiversity influencing malaria, which in turn has improved mapping the malaria risk (Abellana et al., 2008, Ageep et al., 2009). A better and finer risk estimation improves access to target populations; focuses available resources, supports malaria control programs in general as well as improves prevention and intervention measures (Kazembe, 2007; Silue et al., 2008; Riedel et al., 2010). Spatial information has continued significance for current malaria control and elimination strategies. Computer-based support of this kind has been available for a number of years, but it is only recently that it has been widely appreciated as a powerful tool to augment existing monitoring and evaluation methods (Ceccato et al., 2005).

\section{Early use of Earth observation retrieval of data}

Earth observation can be used for the surveillance (Hay et al., 2000), monitoring (Connor et al., 1995) and early warning systems (Ceccato et al., 2005) with respect to vector borne diseases that are closely related to environmental conditions. In epidemiology, links between the physical measurement of reflected radiation by sensors and measures of a disease or vector have been established via logical sequences (Curran et al., 2000, Crombie et al., 1999). For instance, if there is a relationship between land cover/vegetation type and the vector habitats on the one hand and an association between vector habitats and the distribution of the vector-borne disease on the other, remote sensing can provide valuable information on the disease (Curran et al., 2000). Many studies illustrate the linkage between a remotely sensed image and a vector-borne disease, the variation in space and time between image and disease data as well as the derived prediction of vectors density and disease risk.

Remotely sensed images indicating climatic conditions are powerful predictors of vector distribution patterns and the average level of transmission of malaria parasites by these vectors (Rogers et al., 2002). In 1998, the Center for Health Applications of Aerospace Related Technologies (CHAART) at the American National Aeronautics and Space Administration (NASA) evaluated the range of satellite systems for their potential to support epidemiological and entomological research. Many factors were assessed to determine how remote sensing data can be used to explore their potential link to human health (Curran et al., 2000). The authors concluded that the availability and utility of data for studying the spatial and temporal disease patterns was hampered by the sensor performance, data cost and the long turnaround times for product (Curran et al., 2000; Beck et al., 2000). However, this was the situation more than 15 years ago, and the range of new sensors that has become operational since then has extended sensitivity, resolution and turnaround times as well as cost making remote sensing today highly useful for disease surveillance and control. Already in 2005, Ceccato et al. reviewed the capabilities of remote sensing to support operational malaria early warning systems and stated that The time is ripe for the wealth of research knowledge and products from developed countries be made available to the decision-makers in malarious regions of the globe where this information is urgently needed.

Despite the difficulties mentioned, Pope et al. (1994) classified 2 satellite (Landsat-TM) scenes covering the wetlands of the Chiapas area in Mexico according to land cover and correlated this information with vector habitat types to increase the effectiveness of malaria control, while Roberts et al. (1996) investigated the potential of high resolution [in the] visible (HRV) data from the French SPOT satellite for the prediction of the Anopheles mosquito distribution in central Belize. In Africa, Hay et al. (1998) pioneered the use of remotely sensed data showing that the monthly childhood malaria admission (percentage of the annual totals) in three hospitals in Kenya was strongly correlated $\left(r^{2}=0.71\right)$ with the normalized difference vegetation index (NDVI) of the previous month. Since then, the reliance on satellite-generated datasets have grown exponentially as evidenced by reviews by Beck et al. (2000), Ceccato et al. (2005) and Hay et al. (2010) emphasizing ecological factors with influence on malaria development. Very high resolution data from the IKONOS satellite, aerial images and Landsat data were compared by Mushinzimana et al. (2006) for the identification of larval habitats in western Kenya highlands. With a misclassification rate of about $11 \%$ of the IKONOS land cover classification, $40.6 \%$ of the in-field mapped aquatic habitats could be detected $(10.6 \%$ with aerial images and $0 \%$ with Landsat images). Meanwhile, Tatem and Hay (2004) mentioned the suitability of remote sensing for the mapping of the urbanization pattern and extent, which is an important topic in the context of urban public health and malaria. In addition, a link between land cover and the presence of An. darlingi was observed by Zeilhofer et al. (2007) in Mato Grosso, Brazil, while Guerra et al. (2008) used plausible biological constraints upon transmission, based on remotely sensed correlates of vegetation cover, to improve the precision of global distribution of Plasmodium falciparum risk, and Dambach et al. (2009) generated a high-resolution land cover map of a district in Burkina Faso demonstrating a correlation between 10 land cover classes and known breeding sites of the Anopheles mosquito.

The literature reveals that, besides epidemiological research, the use of geo-data have proved to be enormously valuable for the support of malaria control managements, e.g., as demonstrated in the Mpumalanga Province in South Africa (Booman et al., 2000). The integration of geo-data into a computerised malaria control management system allows spatio-temporally monitored spraying coverage, insecticide consumption and application rates (Booman et al., 2003). In order to directly support malaria control actions by EO solutions, different remotely sensed data are required as for epidemiological studies. In particular, imagery with very high resolution can help to identify houses and small huts. Information on their type, amount and distribution is valuable for a more efficient indoor residual spraying (IRS). These data can also be used to derive information on infrastructure (identification of road and path network for logistical planning in remote areas) or to identify small water bodies as potential breeding sites.

In a summary this review identified that EO in malaria control and management addresses two different applications, i.e. applications of 
EO to epidemiology and applications of EO to directly support malaria control actions. Both kinds of applications have different requirements in terms of data type, image analysis approach and updating period.

\section{Study aims}

One of the main aims of MALAREO is to implement EO data usage through capacity building with respect to EO and GIS applications to make them ultimately contribute to the control of malaria in the Lubombo Spatial Development Initiative (LSDI) regions of South Africa, Swaziland, and Mozambique. The focus of this paper is to assess capacity gaps and conduct a needs analysis of E0 and related technologies for malaria vector control and management in these three countries. In order to create a clear and sustainable vision for the future, this study stipulated the following objectives: review local, current EO state-of-art; review the potential for application of EO and spatial epidemiology for malaria vector control and management; review resource requirements; assess the current level of capacity with regard to geoinformation technology and infrastructure for malaria control and management in the project area; assess prioritized end-user requirements; identify gaps in the current, local capacity with regard to EO, GIS and spatial epidemiology for malaria vector control and management; and define a detailed action plan to fill these gaps.

\section{Materials and Methods}

\section{The MALAREO study area}

Early 1999 Swaziland, Mozambique and South Africa launched the Lubombo Spatial Development Initiative (LSDI). This initiative mainly aimed at accelerating development, particularly with regard to agriculture and tourism within an area of approximately 220, 000 square kilometres, covering southern Mozambique, Eastern Swaziland, and NorthEastern South Africa (Figure 1). One objective of the LSDI program is to control the spread of malaria. As a result the malaria control programs have been partly established through the LSDI. The study area of MALAREO coincides with the LSDI activity region.

\section{Evaluation of the capacity status}

This research involved desk review of relevant published and unpublished reports and articles. Secondary data was used to collate and compile available information about LSDI, exploration of the state-of-the art, the E0 satellites currently operational for Africa, their characteristics and common EO data processing techniques and requirements. The main source of information was the Internet and in-house LSDI reports available from the various national MCPs. To prioritise the enduser requirements as well as to evaluate the currently existing capacity and analyse the capacity gap, a questionnaire was designed and managed to gather information on current capacity needs and user requirements at the MALAREO study sites. The domain (EO, GIS and statistical analysis) and objectives of the survey were refined through consultation with all partners. It was decided to focus on the domain of the survey based on i) requirement of EO products for malaria control and management; ii) available capacity to work in a GIS and EO environment to process and analyse spatial data; and iii) to carry out statistical modelling.

\section{Questionnaire design and participants}

The questionnaire included a unique survey of the EO needs in the national MCPs of the study countries. It also examined the current status of the malaria research program capacities with respect to GIS, EO, and spatial epidemiology/statistics assessing the current use, related resources and facilities of these aspects. In addition, the staff opinions regarding the need for training and potential usage of EO were sought. The questionnaire contained two sections gathering information on: i) institutional resources and facilities regarding GIS, EO and spatial epidemiology technologies (in addition, information on current projects, initiatives and future development at each institution was collected); and ii) individual, professional specialties, experience and skills of GIS, EO and statistics, including the level of expertise in the domain area (it also considered staff opinions regarding the importance of EO and related products in their daily activities with reference to malaria control.

The survey was conducted in June 2011 at the MCP of KwaZuluNatal, of Mpumalanga and of Limpopo Provinces, as well as at the Malaria Research Unit (MRU) of the MRC, South Africa. In addition, the survey was also conducted at the national MCP of Swaziland and the national MCP of Mozambique. The institutional section of the survey was completed by the manager of each MCP, while the individual section was distributed to staff members involved in malaria case surveillance, IRS planning, GIS and malaria information systems. The user-based survey employed 43 participants, $25 \%$ of whom were from

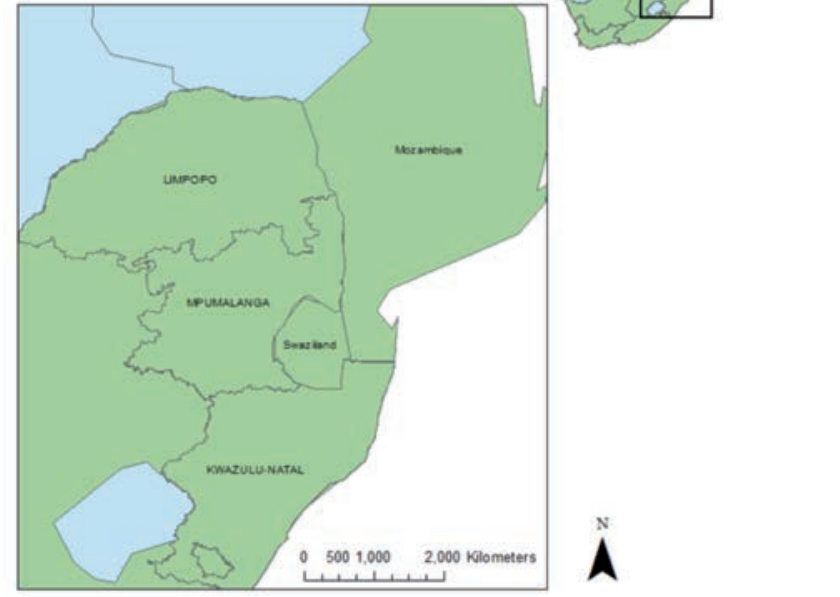

Figure 1. The Lubombo Spatial Development Initiative activity region covering parts of South Africa, Swaziland and Mozambique. 
the Limpopo MCP, 33\% from the KwaZulu-Natal MCP, 20\% from the Swaziland MCP, $18 \%$ from the MRU of the MRC, South Africa and $2 \%$ each from national malaria office in South Africa and the national MCP in Mozambique. The requirements of the institutions can only be assessed using measurable indicators signifying capacity and needs at the institutional level. For each of the different domains, several indicators were identified. For example, digitizing data from hard copy resources, operating GPS and mapping within a GIS platform using existing dataset are indicators of GIS skills, while E0 image ordering, EO image pre-processing, calculation of vegetation indices and feature detection are indicators of EO skills. Indicators of statistics skills include spatial analysis, statistical analysis using statistical software, Bayesian statistical analysis and malaria epidemiology. Those indicators were used to measure the prevailing capacity status in the fields of E0, GIS and statistics in each institution.

Numerous operational satellite sensors are currently available and there are numerous missions planned that will bring further, innovative sensors into space, complementing the current range of sensor systems, or replacing aging sensors to ensure data consistency for long-term monitoring. In order to select those systems that are particularly suitable for malaria control, each sensor characteristic has to be compared to the requirements of the project aims and user requirements. The main constraining sensor characteristics are the spatial and spectral resolution, the swath width, as well as factors such as data costs and access.

\section{Results and Discussion}

\section{Earth observation satellites currently operational over Africa}

Taking the technical characteristics of all sensors in the context of the MALARE0 project objectives into account, various instruments are generally suitable for the purpose. The first Landsat should be mentioned first as it is the longest running enterprise for acquisition of satellite-generated Earth imagery stretching from the launch of Landsat-1 in 1972 to Landsat-8 launched in 2013. The millions of available images, archived in the United States and at Landsat receiving stations around the world, are a unique resource for global change research and applications in that can be viewed at the United States Geological Survey (USGS) dedicated website http://earthexplorer.usgs. gov/. The 'Thematic Mapper (TM)' sensor was first carried on Landsat4 and the latest in the series is the The Enhanced Thematic Mapper Plus (ETM+) carried onboard Landsat satellites 7 and 8 (https://ta.cr.usgs.gov/LETMP).

Instruments such as RapidEye MSI, GeoEye-1, SPOT-5 HRG, THEOS MS, IKONOS-2 MS, QuickBird-2, KOMPSAT-2 MSC, FORMOSAT-2 MS, and WorldView2 have the required spatial and temporal resolution to monitor land cover/land cover change and to discriminate perennial and transient water bodies in the MALARE0 project area. RapidEye MSI, SPOT-5 HRG and THEOS MS have the advantage of a wide swath width and thus cover a large area. RapidEye's satellites are the first commercial satellites to include a band (Red-Edge) sensitive to changes in chlorophyll content. This band can assist in monitoring vegetation health, improve species separation and help in measuring protein and nitrogen content in biomass.

In the context of house distribution mapping, GeoEye-1, IKONOS-2, FORMOSAT-2, QuickBird and WorldView-2 also have high potential to be used for the MALARE0 project, since each sensor has an additional VHR panchromatic band that allows house distribution mapping at great spatial detail. However, these data are comparably costly. Considering SAR systems, COSMO SkyMed and TerraSAR-X are sensor systems that can be considered for their suitability for the MALAREO project due to their high spatial resolution. However, these datasets are also costly. Optical data are mainly used in malaria studies. Table 1 gives an overview of the EO sensors that could be used in MALAREO.

\section{Risk assessment in terms of Earth observation resources}

There are data-related factors with potential, negative implications for the outcome of the MALAREO project results. These risks should be identified as early as possible in order to be able to adapt to given conditions. The most important such factors are availability and affordability, which must be regarded in the context of project duration and sustainability. Data availability is a match between data characteristics as required by the project and existing E0 satellites as well as accessibility (in terms of already acquired data and mission lifetimes). Some cur-

Table 1. Overview of Earth observation sensors of potential use for the MALAREO project.

\begin{tabular}{|c|c|c|c|c|c|c|}
\hline Satellite $^{\circ}$ & Agency \# & Sensor & Spatial resolution & Swath width & (km) Revisit time & Data rights \\
\hline GeoEye-1 & GeoEye & Proprietary specifications & $\mathrm{PAN}^{*}: 0.41 \mathrm{~m} \mathrm{MS}^{* *}: 1.65 \mathrm{~m}$ & 15.2 & $<3$ days & Open access \\
\hline SPOT-5 & CNES & $\mathrm{HRG}$ & $\mathrm{PAN}^{*}: 5 \mathrm{~m} \mathrm{MS} * *: 10 \mathrm{~m}$ & 60 & 2-3 days & Open access \\
\hline IKONOS & GeoEye & Not specified (3D-imagery) & $\mathrm{PAN}^{*}: 1 \mathrm{~m} \mathrm{MS} \mathrm{M}^{* *}: 4 \mathrm{~m}$ & 11 & 3-5 days & Open access \\
\hline RapidEye & BlackBridge & Proprietary specifications & $6.5 \mathrm{~m}$ (recently boosted to $5 \mathrm{~m}$ ) & 78 & Daily & Open access \\
\hline Deimos-1 & Deimos Imaging & Proprietary specifications & $22 \mathrm{~m}$ & 600 & 8 days & Open access \\
\hline QuickBird-2 & DigitalGlobe & Proprietary specifications &  & 16.5 & 2.4-5.9 days & Open access \\
\hline UK-DMC2 & DMCii & Proprietary specifications & $22 \mathrm{~m}$ & 330 & Daily & Open access \\
\hline Landsat-7/8 & ETM+ & USGS/NASA & $15-60 \mathrm{~m}$ & 185 & 16 days & Open access \\
\hline WorldView-2 & DigitalGlobe & DigitalGlobe & $\mathrm{PAN}^{*}: 0.46 \mathrm{~m} \mathrm{MS}^{* *}: 1.84 \mathrm{~m}$ & 16.4 & 1.1-3.7 days & Open access \\
\hline
\end{tabular}

HRG, high resolution geometrical instrument. ${ }^{\circ}$ Deimos-1, Spanish Earth-imaging satellite operated by Deimos Imaging (http:/www.deimos-imaging.com/); QuickBird-2, satellite with high optical resolution imagery collected between 2001 and 2015 owned by DigitalGlobe (https:/www.digitalglobe.com/), it reentered the Earth atmosphere and decayed in January 2015; UK-DMC2, British satellite operated by DMC International Imaging (DMCii) (http://www.dmcii.com/), a Surrey Satellite Technology Ltd subsidiary (http://www.sstl.co.uk/) that manages the disaster monitoring constellation for the international charter for space and major disasters; WorldView-2, https://www.digitalglobe.com/sites/default/files/DG_WorldView2_DS_PROD.pdf \#GeoEye, merged into DigitalGlobe (https:/www.digitalglobe.com/) in 2013; CNES, Centre National d'Etudes Spatiales (the French national space agency); BlackBridge, constellation of 5 satellites originally developed by the German Aerospace Agency (DLR), acquired by and further developed by the Canadian firm BlackBridge (http:/www.blackbridge.com/) in 2011; DigitalGlobe, https:/www.digitalglobe.com/; DMCii, DMC International Imaging; ETM+, Enhanced Thematic Mapper Plus (https://ta.cr.usgs.gov/LETMP).

*Panchromatic resolution; **multispectral resolution. 
rently available satellites are capable of acquiring both high and very high resolution data that are needed by the MALAREO project for land cover assessment and direct support of MCPs. Searches of existing data archives have demonstrated that there are already numerous datasets available for use in the MALARE0 project. In addition, new acquisitions are increasingly becoming available. Hence, data availability will not put the project at risk although data affordability is likely to be a major issue for the MALARE0 end-users since those with very high resolution are still very costly. Therefore, in order to ensure sustainability of project developments, the use of free very high-resolution data such as Google Earth, Bing Maps etc. should be considered.

\section{Earth observation data process requirements}

It is not the purpose of this study to identify and discuss the pros and cons of all possible software applications that could have a bearing on the MALARE0 project. The main objective is instead to consider which types of software are required for the main EO data process steps. Two types of software can be distinguished: commercial-on-the-shelf (COTS) applications (e.g., ERDAS IMAGINE 2011, ENVI, ArcGIS 10.0 and eCognition 8.0) and open-source ones (e.g., GRASS, Q-GIS, Opticks and HealthMapper). This list is by no means comprehensive, but it represents the most common software applications available for image processing. Two levels of expertise exist for assessing the required expertise: i) processing steps executable already after short-term training without previous, high-level education, which can be assigned to E0 technicians/operators, and ii) advanced image analysis and solution formulation, normally assigned to EO technologists/engineers, who have been thoroughly trained as E0 experts and who have attended a more long-term education.

\section{Survey results}

\section{Human resource capacity assessment}

Results from the capacity needs assessment in malaria control programs and institutions (Figure 2) demonstrated that while the majority of the personnel do not have any GIS skills, ten with basic GIS skill and seven with little GIS skills were found. In addition the survey identified that MRC has four GIS expert while NMCP of Swaziland had one GIS expert and none was found in Mozambique. In regard to EO data processing and analysis skills one expert was found at MRC while majority of the candidates do not have any EO skills, except few with little skills. Four of the respondents is found to have an expert level of statistical skills, while most of the respondents have basic statistics skills. Seven of the respondents had little experience in statistics and the remaining had none.

\section{Assessment of product-needs and facility resources}

The survey conducted investigated the perception of the participants towards EO data products, such as temperature, precipitation, vegetation type and altitude, including the distribution of water bodies, populations and households, combination of which makes it possible to predict and outline areas of malaria risk. These products were stratified into three levels of needs, i.e. high, medium and low. The majority of the participants identified these products as highly needed for effective and efficient malaria vector control and management. Table 2 summarizes the impact of these products as stated by many of the participants in surveyed institutions and programs. Here follow some pertinent remarks made by some of the participants: i) These technologies would assist in tracking cases faster and planning and implementing effective IRS; ii) knowledge and understanding of GIS will make it easier for me to generate sound information that will benefit the program; iii) map of household before and after indoor residual spraying would help us for planning and evaluating of the IRS coverage; iv) these technologies will enable us to do the job easier and faster, they would also assist in monitoring and evaluation of IRS. In addition the will assist in dealing with malaria case investigation and quick response to malaria outbreak.

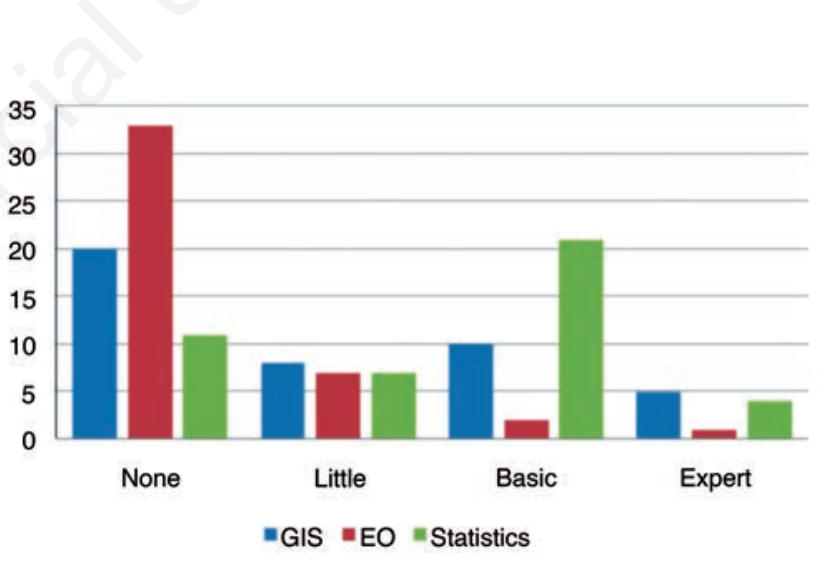

Figure 2. Currently available skills in geographic information systems, Earth observation and spatial statistics in the study area.

Table 2. Earth observation-generated products and their impacts for malaria vector control and management.

\begin{tabular}{ll} 
Focus & Utility and perception \\
Water bodies & Identification of possible vector breeding sites for larviciding \\
Households & Planning and monitoring of IRS*; rapid case-tracking \\
\hline Populations & Identification of malaria risk; calculation of the malaria transmission rate \\
LULC** & Indirect indicator of malaria transmission*** \\
\hline Topography & Indirect indicator of malaria transmission*** \\
Temperature & Indirect indicator of malaria transmission*** \\
\hline Precipitation & Identification of malaria-endemic areas \\
Risk maps & Indication for priority control intervention and risk indicator for visitors \\
\hline Distribution maps & Information on malaria risk and for possible malaria control interventions \\
\hline LULC, land use/land cover. ${ }^{*}$ Indoor residual spraying; ${ }^{* *}$ land use and land cover; $* * *$ most of the participants did not favor this product.
\end{tabular}


Geo-informatics technologies including GIS, GPS and EO as well as spatial epidemiology are thus recognized by many researchers as valuable tools for the support of malaria control measures, increasing the MCP impact, range and efficiency. However, it must be admitted that almost none of the surveyed institutions have a properly implemented infrastructure to utilize these new technologies.

\section{Capacity gap analysis and prioritization}

In a general context, capacity can be expressed as the capability of individuals and institutions to make and implement decisions. This definition includes also how they perform functions, i.e. in an effective, efficient and sustainable manner. The capacity gap analysis framework is comprised of two components: human resources and facility/infrastructure resources (UNDP, 1998), the latter of which are the most important assets within the geo-information framework. Capacity building in the area of human resources is critical with regard to the success of GIS implementation and EO data usage, and it takes also the longest time and is potentially the most expensive part of the process. Given that these assets are the source of creativity and innovation, they are key component of malaria control and elimination strategies. However, effective GIS and EO implementation also requires large storage capacity and specialized computers with dedicated software and transfer facilities.

Exploration and analysis of existing initiatives have shown that there is a high potential for successful malaria control when state-ofthe-art EO applications are utilized. The implementation of operational EO applications in support of malaria control is, however, still at a very early stage. Above all, sustainable implementation requires a guaranteed supply of EO data. Discussion of the actual available EO sensors and EO sensors the planned for the future ensures this condition. To be able to use the diverse advantages offered by various EO sensors and datasets as well as knowledge of ways to develop dedicated instruments and processes for malaria control requires a set of skills that combines knowledge both of malaria epidemiology and satellite-generated remote sensing. It is at this fringe that MALAREO has been operating.

The identified, potential EO applications and infrastructures, the required processing steps and the existing operational EO malaria applications represent together the required skills needed to successfully use EO in support of malaria vector control and management. Different levels of capacity building programs for basic and advanced levels of geo-information technology skills should be envisaged. Basic to advanced GIS skills as well as basic EO knowledge are required at the MCP level, while advanced EO knowledge is required to develop, implement and improve new and existing malaria EO applications. This total capacity is not a requisite at the MCP level, and could well be centralized in a national EO monitoring centre.

\section{Conclusions}

This report not only provides a snapshot of the current EO requirements and capacity gaps in GIS and related technologies in the MCPs of KwaZulu-Natal, Mpumalanga, Limpopo as well as the national MCPs of Swaziland and Mozambique, but addresses also the MRU of the of MRC. Clearly, all MCPs and related institutions are in favor of EO products, including malaria risk mapping for effective malaria vector control and management.
The MALAREO initiative has been addressing two different EO applications for malaria control and management: i) application of remote sensing for malaria epidemiological research, and ii) application of E0 for direct support of malaria control activities. EO epidemiology mainly addresses environmental conditions appropriate for predicting the spatial distribution of the mosquito vector, mainly temperature, precipitation, land cover, land use and NDVI. The EO application that directly supports malaria control activities should provide relevant geo-data capable of optimizing planned control activities, such as selection of homes for IRS and estimating the expanse of areas at risk for malaria. The following EO products are highly important for vector control and targeted interventions: mapping of malaria-endemic areas alerting natives and visitors for the risk; mapping of water bodies as a means for identifying possible vector breeding sites;identification of the distribution of households in need of IRS and monitoring; and population maps to be used to calculate the population at risk for assessment of the prevailing mortality and morbidity rates.

This study has identified a range of issues that are barriers to effective and efficient use of EO products. One major barrier is the lack of skilled personnel employed in the MCPs. Capacity building with respect to GIS, EO and statistics is required to enhance the effectiveness and efficiency of malaria control and management practices. The existing E0 applications should be addressed during capacity building. Different levels of capacity building training programs for basic and advanced level of geo-information technology skills are a necessity, and the establishment of national EO monitoring cells is advised to streamline and enhance data and information flow to the MCPs.

Based on the findings from the assessment section of this report, a set of recommendations can be made, not all of which are in the scope of the MALARE0 project.

First, establish a sustainable link between the MCPs and the academic institutions as a basis for capacity building. In MALARE0, this link should be established and consolidated with the University of KwaZulu-Natal and the Swiss TPH. Second, establish a basic and advanced GIS short-course program, preferably based on open-source software. Third, develop a framework for spatial data collection and information flow between the MRC and the GIS officer of each MCP in the LSDI area. Fourth, develop a set of EO products in line with enduser requirements that can be used for demonstration of the use of EO products. Fifth, contribute to the establishment and utilization of stateof-the-art E0 applications for malaria epidemiology in order to get required information for effective malaria vector control and management. Sixth, establish and build a fundamental EO data processing and analysis centre for the support of the MCPs of South Africa, Swaziland and Mozambique. Seventh, streamline and enhance information flows between the EO call centre and the MCPs. Eighth, create GIS positions in the MCPs in KwaZulu-Natal , Mpumalanga and Limpopo as well as in the national MCPs in Mozambique. This position would significantly increase the analysis of spatial data and thus support MCP activities, including IRS planning and case detection. It would further fill the gap in spatial data collection and quality control as well as support model development and general maintenance. Nineth, foresee the necessary GIS infrastructure in all MCPs of South Africa and the national MCP in Mozambique. Lastly, create a new GIS viewer or refurbish the spatial LUBOMBO GIS viewer with new features that can speed information distribution to the MCPs. 


\section{References}

Abellana R, Ascaso C, Aponte J, Saute F, Nhalungo D, Nhacolo A, Alonso $\mathrm{P}, 2008$. Spatio-seasonal modelling of the incidence rate of malaria in Mozambique. Malaria J 7:228.

Ageep TB, Cox J, Hassan MM., Knols BG, Benedict MQ, Malcolm CA, Babiker A, El-Sayed B, 2009. Spatial and temporal distribution of the malaria mosquito Anopheles arabiensis in northern Sudan: influence of environmental factors and implications for vector control. Malaria J 2009:123.

Beck LR, Bradley ML, Wood BL, 2000. Remote sensing and human health: new sensors and new opportunities. Emerg Infect Dis 6:217-66.

Booman M, Durrheim DN, La Grange K, Martin C, Mabuza AM, Zitha A, Mbokazi FM, Fraser C, Sharp BL, 2000. Using a geographical information system to plan a malaria control programme in South Africa. B World Health Organ 78:1438-44.

Booman M, Sharp BL, Martin CL, Manjate B, La Grange JJ, Durrheim DN, 2003. Enhancing malaria control using a computerised management system in southern Africa. Malaria J 2:13.

Brooker S, Utzinger J, 2007. Integrated disease mapping in a polyparasitic world. Geospat Health 1:141-6.

Ceccato P, Connor SJ, Jeanne I, Thomson MC, 2005. Application of geographic information systems and remote sensing technologies for assessing and monitoring malaria risk. Parassitologia 47:81-96.

Connor SJ, Thomson MC, Flasse SP, Williams JB, 1995. The use of lowcost remote sensing and GIS for identifying and monitoring the environmental factors associated with vector borne disease transmission. Available from: http://www.idrc.ca/EN/Resources/Publications/openebooks/2856/index.html\#page_75

Crombie MK, Gillies RR, Arvidson RE, Brookmeyer P, Weil GJ, Sultan M, Harb M, 1999. An application of remotely derived climatological fields for risk assessment of vector-borne diseases: a spatial study of filariasis prevalence in the Nile Delta, Egypt. Photogramm Eng Rem S 65:1401-10.

Curran PJ, Atkinson PM, Foody GM, Milton EJ, 2000. Linking remote sensing, land cover and disease. Adv Parasitol 47:37-78.

Dambach P, Sié A, Lacaux JP, Vignolles V, Machault V, Sauerborn R, 2009. Using high spatial resolution remote sensing for risk mapping of malaria occurrence in the Nouna district, Burkina Faso. Glob Health Action 2009:10.3402.

Gemperli A, Vounatsou P, Kleinschmidt P, Bagayoko L, Lengeler M, Smith C, 2004. Spatial Patterns of infant mortality in Mali: the effect of malaria endemicity. Am J Epidemiol 159:64-72.

Gething PW, Atkinson PM, Noor AM, Gikandi PW, Hay SI, Nixon MS, 2007. A local space-time kriging approach applied to national outpatient malaria data set. Comput Geosci 33:1337-50.

Global Malaria Action Plan. Roll Back Malaria, 2010. Available from: http://www.rollbackmalaria.org/gmap/

Guerra CA, Gikandi PW, Tatem AJ, Noor AM, Smith DL, Hay SI, Snow RW, 2008. The limits and intensity of Plasmodium falciparum transmission: implications for malaria control and elimination worldwide. PLoS Med 5:300-11.

Hay SI, Omumbo JA, Craig MH, Snow RW, 2000. Earth observation, geographic information systems and Plasmodium falciparum malaria in Sub-Saharan Africa. Advanced Parasitol 47:173-215.

Hay SI, Packer MJ, Rogers DJ, 2010. Review article. The impact of remote sensing on the study and control of invertebrate intermediate hosts and vectors for disease. Int J Remote Sens 18:2899-930.
Hay SI, Snow RW, Rogers DJ, 1998. From predicting mosquito habitat to malaria seasons using remotely sensed data: practice, problems and perspectives. Parasitol Today 14:306-13.

Hayes R0, Maxwell EL, Mitchell CJ, Woodzick TL, 1985. Detection, identification, and classification of mosquito larval habitats using remote sensing scanners in earth-orbiting satellites. B World Health Organ 63:361-74.

Kazembe LN, 2007. Spatial modelling and risk factors of malaria incidence in northern Malawi, Acta Trop 102:126-37.

Kleinschmidt I, Bagayoko M, Clarke GP, Craig M, Le Sueur D, 2000. A spatial statistical approach to malaria mapping. Int J Epidemiol 29:355-61.

MARA, 1998. Towards an atlas of malaria risk in Africa: first technical report of the MALARA/ARMA collaboration. Mapping Malaria Risk in Africa, Durban, South Africa.

Mirghani SE, Nour BYM, Bushra SM, Elhassan IM, Snow RW, Noor AM, 2010. The spatial-temporal clustering of Plasmodium falciparum infection over eleven years in Gezira State, The Sudan. Malaria J 9:172.

Mushinzimana E, Munga S, Minakawa N, Li L, Feng C-C, Bian L, Kitron U, Schmidt C, Beck L, Zhou G, Githeko AK, Yan G, 2006. Landscape determinants and remote sensing of anopheline mosquito larval habitats in the western Kenya highlands. Malaria J 5:13.

Omumbo JA, Ouma J, Rapuoda B, Craig MH, le Sueur D, Snow RW, 1997. Mapping malaria transmission intensity using Geographical Information Systems (GIS); an example from Kenya. Ann Trop Med Parasit 92:7-21.

Pope KO, Rejmankova E, Savage HM, Arredondo-Jimenez JI, Rodriguez MH, Roberts DR, 1994. Remote sensing of tropical wetlands for malaria control in Chiapas, Mexico. Ecol Appl 4:81-90.

Riedel N, Vounatsou P, Miller JM, Gosoniu L, Chizema-Kawesha E, Mukonka V, Steketee RW, 2010. Geographic patterns and predictors of malaria risk in Zambia: Bayesian geostatistical modelling of the 2006 Zambia national malaria indicator survey. Malaria J 9:37.

Roberts DR, Paris JF, Manguin S, Harbach RE, Woodruff R, Rejmankova E, Polanco J, Wullschleger B, Legters LJ, 1996. Predictions of malaria vector distribution in Belize based on multispectral satellite data. Am J Trop Med Hyg 54:304-8.

Rogers DJ, Randolph SE, Snow RW, Hay SI, 2002. Satellite imagery in the study and forecast of malaria. Nature 415:710-5.

Roll Back Malaria, 2011. Roll Back Malaria partnership: refined/updated GMAP objectives, targets, milestones and priorities beyond 2011 as agreed upon by the RBM Board on 12 June 2011, based on the recommendations of the RBM task force on priorities and targets beyond 2011. Roll Back Malaria partnership, Geneva, Switzerland.

Silue KD, Raso G, Yapi A, Vounatsou P, Tanner M, Goran EKN, Utzinger J, 2008. Spatially-explicit risk profiling of Plasmodium falciparum infections at a small scale: a geo-statistical modelling approach. Malaria J 7:11.

Sipe N, Dale P, 2003. Challenges in using geographic information systems (GIS) to understand and control malaria in Indonesia. Malaria J 2:36.

Smith T, Charlwood JD, Takken W, Tanner M, Spiegelhalter DJ, 1995. Mapping the densities of malaria vectors within a single village. Acta Trop 59:1-18.

Snow RW, Craig MH, Deichmann U, Le Sueur DA, 1999. preliminary continental risk map for malaria mortality among African children. Parasitol Today 15:99-104.

Tanser FC, Le Sueur D, 2002. The application of geographic information systems to important public health problems in Africa. Int $\mathbf{J}$ Health Geogr 1:4. 
Tatem AJ, Hay SI, 2004. Measuring urbanization pattern and extent for malaria research: a review of remote sensing approaches. J Urban Health 81:363-76.

Webster J, Lines J, Bruce J, Armstrong S JR, Hanson K, 2005. Which delivery systems reach the poor? A review of the equity of coverage of ever-treated nets, never-treated nets, and immunisation to reduce child mortality in Africa. Lancet Infect Dis 5:709-17.
WHO, 2011. World malaria report 2011. World Health Organization, Geneva, Switzerland.

Zeilhofer P, dos Santos ES, Ribeiro ALM, Miyazaki RD, dos Santos MA, 2007. Habitat suitability mapping of Anopheles darlingi in the surroundings of the Manso hydropower plant reservoir, MatoGrosso, Central Brazil. Int J Health Geogr 6:7-14. 